\title{
Detrimental sublethal effects hamper the effective use of natural and chemical pesticides in combination with a key natural
} enemy of Bemisia tabaci on tomato

\author{
Marianne A Soares, ${ }^{a, b *}$ Geraldo A Carvalho, ${ }^{\text {a Mateus R Campos, }}{ }^{\text {b }}$ \\ Luis C Passos, ${ }^{a, c}$ Marcelo M Haro, ${ }^{\text {d }}$ Anne-Violette Lavoir, ${ }^{b}$ Antonio Biondi, ${ }^{c}$ \\ Lucia Zappalàc and Nicolas Desneux ${ }^{b}$
}

\begin{abstract}
Background: Bemisia tabaci (Hemiptera: Aleyrodidae) represents one of the greatest threats to agricultural crops. Chemical con-trol is the primary tool used in integrated pest management (IPM) programs. However, release of the predator Nesidiocoris ten-uis (Hemiptera: Miridae) on tomato plants is a highly recommended control tactic. The objective of this study was to evaluate the efficacy of a commercial borax plus citrus oil (BCO) product against $B$. tabaci in the presence and absence of $N$. tenuis. The synthetic insecticide lambda-cyhalothrin was used as a positive control. We also evaluated the sublethal effects of BCO on the

behavior and predation rate of $\boldsymbol{N}$. tenuis.

Results: Our results demonstrated that $B C O$, alone and at its maximum recommended field rate for $B$. tabaci, was not effective in controlling the pest under laboratory conditions. Application of BCO simultaneous with $N$. tenuis release did not reduce the increase in the B. tabaci population. Effective control of B. tabaci was achieved using only N. tenuis. However, synthetic lambda-cyhalothrin pyrethroid, used here as a control, caused high pest mortality and led to on-site extinction of $\mathbf{N}$. tenuis, which did not occur for insects exposed to BCO. Lambda-cyhalothrin and BCO significantly affected the foraging behavior of N. tenuis, reducing the predation rate, especially following exposure to lambda-cyhalothrin.
\end{abstract}

Conclusion: The insecticide lambda-cyhalothrin achieved satisfactory results in suppressing B. tabaci, but was harmful to $N$. tenuis. Additionally, lambda-cyhalothrin and BCO affected predator behavior.

Keywords: biological control; ecotoxicology; integrated pest management; predatory mirids; whitefly

\section{INTRODUCTION}

The silverleaf whitefly, Bemisia tabaci Gennadius (Hemiptera: Aleyrodidae) (MED - biotype Q), is one of the most devastating pests of several crops, and is of global economic importance. ${ }^{1,2}$ The whitefly is highly polyphagous, feeding on and damaging $\sim 500$ host plants, including ornamentals, vegetables, legumes, cotton, and corn. ${ }^{2-5}$ This herbivore can cause damage to plants through direct phloem feeding; however, the greatest threat is due to the transmission of plant pathogens during feeding. ${ }^{6,7}$ In addition, $B$. tabaci excretes 'honeydew' while feeding on the plant, favoring the growth of opportunistic fungi, reducing plant photosynthesis, and consequently causing yield losses. ${ }^{2,8}$

Management of $B$. tabaci populations and the plant diseases transmitted by this polyphagous insect represents a challenge for farmers and researchers. ${ }^{9}$ Difficulty in controlling whiteflies results from their rapid population growth, ability to develop resistance to conventional insecticides, and their biological development characteristics in that all life stages (eggs, nymphs and adults) remain protected in the abaxial leaf surface of the host plant. ${ }^{1,3}$ Tomato production systems usually require the use of insecticides to control B. tabaci, and in most cases, this tool is used in an inadequate manner. ${ }^{10}$ This practice has triggered resistance to several conventional insecticides with different modes of action in various $B$. tabaci populations. ${ }^{11}$ Cases of resistance are

\footnotetext{
Correspondence to: MA Soares, Universidade Federal de Lavras, Câmpus Universitário, Caixa Postal 3037, CEP 37200-900, Lavras -MG, Brazil, E-mail: marianne_bio@hotmail.com

a Laboratório de Ecotoxicologia e MIP, Departamento de Entomologia, Universidade Federal de Lavras, Lavras, Brazil

b University Côte d'Azur, INRAE, CNRS, UMR ISA, Nice, France

c Department of Agriculture Food and Environment, University of Catania, Catania, Italy

d Laboratório de Entomologia, Estação Experimental de Itajaí, Empresa de Pesquisa Agropecuária e Extensão Rural de Santa Catarina (Epagri), Santa Catarina, Brazil
} 
related to modulators of nicotinic acetylcholine receptors (e.g., neonicotinoids), molecules that act on the nerves and muscles of insects (e.g., pyrethroids, organophosphosphates compounds, and diamides) and a wide variety of growth-regulator insecticides. $^{10,12-14}$

The appropriate use of zoophytophagus predators is a safe alternative to pesticides for controlling pests in tomato crops. Additionally, these predators can be combined with other natural enemy insects (e.g., parasitoids), natural pathogens (e.g., fungi, nematodes, bacteria, and viruses) or selective insecticides (e.g., the diamide chemical group). ${ }^{15-21}$ Among the natural enemies studied for the control of Solanaceae pests, are the predators Macrolophus pygmaeus (Rambur) and Nesidiocoris tenuis (Reuter) (Hemiptera: Miridae), which are considered to be efficient naturally occurring and/or commercialized agents for biological control against several herbivorous arthropods in Europe, Asia, and Africa. ${ }^{22-25}$ These predators are able to feed on various small pests (e.g., whiteflies, aphids, mites, and lepidopterans), ${ }^{26-28}$ move over the trichomes of plants to a satisfactory degree, and females lay their eggs endophytically in tomato leaves. ${ }^{29}$

Because of possible mortality (acute toxicity) and several sublethal physiological and behavioral effects of non-selective insecticides in beneficial arthropods, ${ }^{30,31}$ active compounds derived from plants may be an alternative to other types of pesticides for use in integrated pest management (IPM). ${ }^{32-37}$ Botanical pesticides may be used as isolated substances or complex mixtures, and their range of action includes their use as insecticides, fungicides, nematicides, and bactericides. ${ }^{38}$ However, before including new products in IPM programs, it is necessary to know the effects of these botanical insecticides on target and non-target species. Approaches that use population models can provide useful population dynamics predictions based on individual-level parameters. ${ }^{39,40}$ Thus, the harmful effects of insecticides on population levels of pests and natural enemies can be estimated based on the life history parameters of these organisms. ${ }^{41-46}$

This study explored the potential of a commercial product based on borax plus citrus oil (BCO) combined with the predator $N$. tenuis as a tool for whitefly control. The objectives of this study were to: (i) provide information on the population growth of $B$. tabaci following exposure to BCO and a standard synthetic insecticide (lambda-cyhalothrin) in the presence and absence of $N$. tenuis; (ii) determine the influence of the botanical insecticide and conventional insecticide on population growth in $N$. tenuis; and (iii) evaluate possible sublethal effects on the foraging behavior and predation rate of $N$. tenuis following exposure to BCO and lambda-cyhalothrin.

\section{MATERIALS AND METHODS}

\subsection{Biological materials}

Bioassays were performed at the National Agronomic Research Institute (INRA; Sophia-Antipolis) in France under controlled laboratory conditions $\left(25 \pm 2{ }^{\circ} \mathrm{C}, 75 \pm 10 \%\right.$ relative humidity $(\mathrm{RH})$ and 16:8 h light/dark photoperiod). Tomato and tobacco plants (Solanum lycopersicum cv. Marmande and Nicotiana tabacum var. Wild) were cultivated in a climatic chamber $\left(25 \pm 2{ }^{\circ} \mathrm{C}, 75 \pm 5 \% \mathrm{RH}\right.$ and 16:8 h light/dark photoperiod) on a commercial substrate (Tournesol ${ }^{\oplus}$, Nice, France) in plastic pots $(2 \mathrm{~L})$, without receiving pesticide applications.

Bemisia tabaci (biotype Q) was maintained on tobacco plants in a climatized room $\left(25 \pm 2{ }^{\circ} \mathrm{C}, 75 \pm 5 \% \mathrm{RH}\right.$ and $116: 8 \mathrm{~h}$ light/dark photoperiod). Whiteflies were kept on two tobacco plants (20 and 40 days old) in an anti-aphid cage made by covering a wooden cage $\left(100 \times 100 \times 75 \mathrm{~cm}^{3}\right)$ with an insect-proof net $(50$ mesh). Plants were irrigated three times a week. Once a month, a new tobacco plant was offered to the colony and the oldest plant was discarded.

The predator $N$. tenuis and an alternative prey Ephestia kuehniella Zeller (Lepidoptera: Pyralidae) were supplied by Koppert Biological Systems (Almeria, Spain). Predators were kept on tobacco plants $(\sim 40$ days old $)$ in a plastic cage $\left(60 \times 60 \times 40 \mathrm{~cm}^{3}\right)$ covered by an insect-proof net (50 mesh). Nesidiocoris tenuis was fed on E. kuehniella eggs. Adult predators were transferred to a new plant once a week, on which females could lay eggs over a period of 1 week. Thus, predators of a similar instar were kept together inside the anti-aphid cage to minimize cannibalism by larger insects. ${ }^{47}$

\subsection{Insecticides}

Prev-Am ${ }^{\circledast}$ (borates tetrasodium salts and $60 \mathrm{~g}$ of orange oil per liter; ORO AGRI Internacional Ltda., Gennevilliers, France), referred to as BCO in this study, is produced from sweet orange peel oil and is used as an alternative pest control agent in agroecological systems. To evaluate the demographic parameters of $B$. tabaci and $N$. tenuis, bioassays were performed using three BCO concentrations, namely, the maximum concentration recommended to control whiteflies in the field $\left(0.2352 \mathrm{~g}\right.$ a.i. $\left.\mathrm{L}^{-1}\right)$, half of the maximum concentration $\left(0.1176 \mathrm{~g}\right.$ a.i. $\left.\mathrm{L}^{-1}\right)$, and $10 \%$ of the maximum concentration $\left(0.0235 \mathrm{~g}\right.$ a.i. $\left.\mathrm{L}^{-1}\right)$. The predation bioassay was performed using only the maximum concentration of this product.

Karate Zeon ${ }^{\circledR} 100$ EC (Syngenta International Ltda., Milano, Italy) is a commercial formulation of the pyrethroid insecticide lambdacyhalothrin, which is widely used to control pests in agricultural systems. It was used as a positive control at the maximum recommended concentration to control whiteflies $\left(0.0237 \mathrm{~g}\right.$ a.i. $\left.\mathrm{L}^{-1}\right)$ in the bioassays of demographic parameters and predation behavior.

The given concentration were obtained by diluting Karate Zeon $^{\oplus}$ and Prev-Am ${ }^{\oplus}$ in distilled water, which alone served as negative control.

\subsection{Estimating the demographic parameters of Bemisia tabaci and Nesidiocoris tenuis}

The bioassays aimed to determine the mean offspring and the population growth of $B$. tabaci (ten treatments, of which five had added predators and five had no predators) and $N$. tenuis (five treatments). In both bioassays, 20 replicates were performed per treatment.

Adults of $B$. tabaci and $N$. tenuis were exposed to dry residues of lambda-cyhalothrin and BCO on tomato leaves. Tomato leaves with fully expanded leaflets ( $15 \mathrm{~cm}^{2}$, composed of five leaflets) were immersed in BCO (in one of the three concentrations: 0.2352, 0.1176 and $0.0235 \mathrm{~g}$ a.i. $\left.\mathrm{L}^{-1}\right)$, lambda-cyhalothrin $(0.0237 \mathrm{~g}$ a. i. $\mathrm{L}^{-1}$ ) or distilled water for $5 \mathrm{~s}$. The leaves were left to dry for $1 \mathrm{~h}$ and placed inside a system composed of overlapping plastic cups, as an experimental unit proposed by Biondi et $a l^{48}$ The plastic cup (700 mL, length: $15 \mathrm{~cm}$ ) had a hole in the bottom center to allow the leaf stem to reach a second plastic cup $(350 \mathrm{~mL}$, length: $11 \mathrm{~cm}$ ) below that contained water. Subsequently, a fine mesh net was fixed in the upper opening of the first upper cup to permit ventilation and prevent insects from escaping.

To evaluate the demographic parameters of $B$. tabaci, four pairs of whiteflies ( $\sim 2$ days old) were maintained in each experimental unit. In treatments comprising $B$. tabaci plus predator, one $N$. 
tenuis female ${ }^{49}$ ( $\sim 2$ days old) was also added. Additionally, to evaluate the demographic parameters of $N$. tenuis, two pairs ${ }^{49}$ of predators ( $\sim 8$ days old) were maintained on tomato leaves in the experimental unit described above.

Eleven days after the beginning of each bioassay, living offspring of the whiteflies and predators at each stage of life cycle were counted under a stereomicroscope ( $\times 40$ magnification). The evaluation time was that proposed by Walthall and Stark. ${ }^{50}$

\subsection{Effects of insecticides on the foraging behavior and predation rate of Nesidiocoris tenuis}

Bioassays to determine behavioral response and predation rate of $N$. tenuis were performed using $B$. tabaci (second instar) nymphs as prey, and were performed with three treatments ( $B C O$, lambda-cyhalothrin and untreated control). Twenty replicates were performed for each treatment.

Untreated tomato leaves were previously offered to $B$. tabaci adults for $24 \mathrm{~h}$ so the insects could lay eggs. After 13 days, excess nymphs were removed, leaving 150 whitefly nymphs (second instar) in each replicate.

Nesidiocoris tenuis females ${ }^{49}$ ( $\sim 2$ days old) were kept on treated tomato leaves, and starved for $24 \mathrm{~h}$. Leaves were treated with a $\mathrm{BCO}$ or lambda-cyhalothrin solutions, both at the maximum concentrations recommended for the control of whiteflies, as previously described. Distilled water was used as a negative control.

Predators were subsequently isolated in Petri dishes $(10 \mathrm{~cm}$ diameter $\times 2 \mathrm{~cm}$ height) containing an untreated tomato leaflet infested with B. tabaci nymphs in an agar-water solution (1\%). Petri dishes were closed with Teflon ${ }^{\circledast}$ film to prevent insects escaping.

Predator activity was recorded for $10 \mathrm{~min}$ per replicate. Thus, five actions were simultaneously recorded in real time: walking, cleaning, feeding on plants, preying on $B$. tabaci and resting. Time spent on each action was recorded using ETHOWATCHER ${ }^{\oplus}$ software. $^{51}$

The second step was to evaluate the predation rate of $N$. tenuis. Thus, after the behavioral assay, predators were kept in the Petri dish described above, and their predation rate (i.e., the number of preyed on whitefly nymphs) was recorded 12 and $24 \mathrm{~h}$ after the start of the experiment.

\subsection{Statistical analyses}

Data were subjected to tests of normality (Shapiro-Wilk) ${ }^{52}$ and homoscedasticity (Bartlett). ${ }^{53}$ Subsequently, the number of $B$. tabaci and $N$. tenuis nymphs at each instar was subjected to an analysis of variance (PROC ANOVA) and Tukey's test to detect the differences between the treatments $(P<0.05)$ (PROC GLM).

The demographic parameters of $B$. tabaci and $N$. tenuis were evaluated using the instantaneous rate of increase $\left(r_{i}\right)$, based on the equation proposed by Walthall and $\mathrm{Stark}^{50}$ as follows:

$$
r_{i}=\frac{\ln \left(\frac{N}{N_{0}}\right)}{\Delta t}
$$

where $N_{\mathrm{f}}$ is the final number of living insects, $N_{0}$ is the initial number of insects, and $\Delta t$ is the time interval (days) from the beginning to the end of the laboratory experiments. ${ }^{41,50}$ Subsequently, the population growth of $B$. tabaci and $N$. tenuis was estimated according to the equation below:

$$
\frac{\mathrm{dN}}{\mathrm{dt}}=\mathrm{rN} \frac{K-N}{K}
$$

Where $N$ is the initial population size, which represents the initial number of $B$. tabaci or $N$. tenuis used in each experimental unit. $r$ represents the per capita growth rate (capacity of each $B$. tabaci or $N$. tenuis to produce descendants). In earlier trials, the carrying capacity of the arenas was determined, based on the approximate number of insects in natural colonized plants, which was represented by the $K$ value; $(K-N)$ is the unused capacity. Growth curves were adjusted using Kaplan-Meier estimators from the non-parametric procedure (PROC LIFETEST). Similarities between the timeresponse curves were tested in paired comparisons $\chi^{2}$ log-rank test) between the curves.

Canonical variate analysis (CVA) of predator behaviors (walking, cleaning, plant feeding, preying, and resting) when subjected to different treatments was performed to recognize possible differences and the main behavior contributing to the observed differences (PROC CANDISC with the Distance statement).

Finally, differences in the predation rates between times and among treatments were analyzed by Generalized Linear Models (GLM's) following a Poisson distribution. All analyses were performed in SAS v. 9.2 (SAS Institute, Cary, NC, USA), except for the predation rate analyses, which were performed using ' $R$ ' 3.4.4 (R Foundation for Statistical Computing, Vienna, Austria).

\section{RESULTS}

\subsection{Estimating the demographic parameters of Bemisia tabaci}

In the absence of $N$. tenuis, whitefly females laid more eggs on treatments exposed to distilled water and the minimum concentration of BCO (Table 1). Bemisia tabaci females reduced their oviposition when exposed to half-maximum and maximum concentrations of BCO. The lowest number of eggs was reported for the lambda-cyhalothrin treatment. The number of first instar nymphs found in the distilled water treatment did not differ significantly from the insects exposed to the minimum concentration of $\mathrm{BCO}$. The number of nymphs found at the maximum concentrations of BCO and lambda-cyhalothrin treatments was lower than with other treatments. For second instar nymphs, the highest number of offspring was found for insects in distilled water and the minimum BCO concentration; the lambda-cyhalothrin treatment had the lowest number of nymphs. At the third instar, there were no significant differences in the numbers of offspring for insects exposed to minimum and half the recommended BCO concentrations. Finally, the lowest number of nymphs was found in the lambdacyhalothrin treatment (Table 1).

In the presence of $N$. tenuis, the lowest number of $B$. tabaci eggs was obtained in the control and lambda-cyhalothrin treatments. Regarding the first instar of B. tabaci, the lowest number of nymphs was observed in the distilled water and lambda-cyhalothrin treatments. For the second instar of B. tabaci, the largest number of descendants was found in treatments containing the half and maximum concentrations of BCO. In addition, a lower number of $B$. tabaci nymphs was observed in the distilled water and lambda-cyhalothrin treatments. With respect to the third instar, the largest number of $B$. tabaci nymphs was observed at the half-maximum concentration of BCO. Additionally, no significant differences were observed between treatments composed of distilled water, maximum BCO concentration and lambda-cyhalothrin (Table 1). 


\begin{tabular}{|c|c|c|c|c|c|}
\hline \multirow[b]{2}{*}{ Treatment } & & \multicolumn{4}{|c|}{ Absence of Nesidiocoris tenuis* } \\
\hline & & Eggs & First instar & Second instar & Third instar \\
\hline \multirow[t]{5}{*}{ B. tabaci +} & Distilled water & $325.9 \pm 12.1 \mathrm{a}$ & $38.3 \pm 2.8 \mathrm{a}$ & $308.9 \pm 9.1 \mathrm{a}$ & $55.6 \pm 4.9 a$ \\
\hline & BCO $10 \%$ & $300.1 \pm 10.2 \mathrm{a}$ & $37.4 \pm 2.9 \mathrm{a}$ & $274.1 \pm 6.9 \mathrm{ab}$ & $40.4 \pm 4.0 \mathrm{~b}$ \\
\hline & BCO 50\% & $221.4 \pm 13.9 b$ & $26.8 \pm 2.5 b$ & $246.6 \pm 14.9 b$ & $37.2 \pm 3.4 b$ \\
\hline & BCO $100 \%$ & $117.4 \pm 14.3 c$ & $5.9 \pm 0.9 c$ & $167.7 \pm 12.1 c$ & $14.2 \pm 1.8 \mathrm{c}$ \\
\hline & Lambda-cyhalothrin & $1.3 \pm 0.5 \mathrm{~d}$ & $0.1 \pm 0.1 \mathrm{c}$ & $1.1 \pm 0.4 \mathrm{~d}$ & $1.1 \pm 0.4 \mathrm{~d}$ \\
\hline \multicolumn{2}{|l|}{$F_{4,95}$} & 139.58 & 67.69 & 150.05 & 43.81 \\
\hline \multirow[t]{3}{*}{$P$} & & $<0.001$ & $<0.001$ & $<0.001$ & $<0.001$ \\
\hline & & \multicolumn{4}{|c|}{ Presence of Nesidiocoris tenuis* } \\
\hline & & Eggs & First instar & Second instar & Third instar \\
\hline \multirow[t]{5}{*}{ B. tabaci +} & Distilled water & $17.1 \pm 3.0 \mathrm{c}$ & $1.6 \pm 0.3 c$ & $27.1 \pm 4.2 c$ & $1.5 \pm 0.4 c$ \\
\hline & BCO 10\% & $68.4 \pm 7.0 \mathrm{~b}$ & $5.7 \pm 0.8 b$ & $104.1 \pm 10.3 \mathrm{a}$ & $11.4 \pm 2.1 b$ \\
\hline & BCO $50 \%$ & $109.9 \pm 11.0 \mathrm{a}$ & $20.6 \pm 1.6 \mathrm{a}$ & $103.5 \pm 7.5 \mathrm{a}$ & $26.2 \pm 1.5 \mathrm{a}$ \\
\hline & BCO 100\% & $88.1 \pm 12.2 \mathrm{ab}$ & $8.0 \pm 1.0 \mathrm{~b}$ & $66.5 \pm 9.5 b$ & $5.2 \pm 1.4 c$ \\
\hline & Lambda-cyhalothrin & $1.4 \pm 0.4 c$ & $0.5 \pm 0.2 c$ & $1.3 \pm 0.4 c$ & $1.2 \pm 0.4 c$ \\
\hline$F_{4,95}$ & & 32.55 & 71.26 & 38.49 & 61.84 \\
\hline$P$ & & $<0.001$ & $<0.001$ & $<0.001$ & $<0.001$ \\
\hline
\end{tabular}

The treatment consisting solely of $B$. tabaci, B. tabaci $+\mathrm{BCO}$ (minimum concentration), and B. tabaci + BCO (half concentration) resulted in the greatest population growth capacity. Bemisia tabaci $+N$. tenuis resulted in fewer B. tabaci nymphs. However, the lowest number of $B$. tabaci offspring was found on tomato leaves treated with lambda-cyhalothrin (Fig. 1).

\subsection{Estimation of demographic parameters for Nesidiocoris tenuis}

For the three BCO concentrations and lambda-cyhalothrin, the number of $N$. tenuis nymphs that emerged from tomato leaves was significantly lower than for insects exposed in the untreated control. Emergence of first and fourth instar nymphs was significantly lower in BCO treatments (three concentrations) than in the untreated control. With respect to second instar nymphs, the three concentrations of BCO also reduced emergence. The half and maximum recommended concentrations of $\mathrm{BCO}$ were more toxic for the third instar nymphs. Nesidiocoris tenuis adults did not reproduce when exposed to lambda-cyhalothrin (Table 2).

Although the three BCO concentrations reduced the mean number of offspring of $N$. tenuis, analysis of the demographic parameters showed positive population growth for predators exposed to BCO treated leaves (Fig. 2). In addition, the increase in the population of predators exposed to the minimum BCO concentration was similar to that for the untreated control. However, the same was not observed for insects exposed to lambda-cyhalothrin, which did not show any capacity for population growth following exposure to the synthetic insecticide (Fig. 2).

\subsection{Effects of insecticides on the foraging behavior and predation rate of Nesidiocoris tenuis}

CVA indicated significant global differences in the behavior of the predator insects when subjected to different treatments (Wilks $\lambda=0.61 ; F=2.93 ; d f$ (num $/$ den) $=10 / 106 ; P=0.002$ ) (Table 3 ).
The CVA diagram suggests that the lambda-cyhalothrin and BCO treatments affected predator behavior compared with the untreated control (Fig. 3). The first axis $(P=0.002)$ explained $98 \%$ of the observed differences (Table 3 ). Higher canonical loads were observed in cleaning and predation behavior on the first axis, which were responsible for most of the divergence observed between the treatments.

$N$. tenuis individuals exposed to BCO and lambda-cyhalothrin predated fewer $B$. tabaci nymphs than those in the untreated control. Moreover, the interaction between time factors and treatments showed significant differences in the reduction in the predation rate $\left(\chi^{2}=8.42, d f=2, P=0.015\right)$. The lowest number of predated $B$. tabaci nymphs was observed for predators exposed to lambda-cyhalothrin, and the highest number was observed for predators treated with distilled water $\left(\chi^{2}=67.40, d f=2\right.$, $P<0.001)$. In all treatments, predators preyed more during the first evaluation period $(1-12 \mathrm{~h})$ than during the second $\left(12-24\right.$ h) $\left(\chi^{2}=1443.62, d f=1, P<0.001\right)$ (Fig. 4).

\section{DISCUSSION}

Insecticides have been widely used in tomato and other crops due to their effective pest control and rapid action against susceptible populations of B. tabaci. ${ }^{54}$ However, environmentally safe approaches (e.g., combining natural enemies and selective products) should be prioritized to avoid a build-up of insecticide resistance. ${ }^{11,55,56}$ In our study, the $B$. tabaci population was able to increase when exposed to dry residues of BCO on tomato leaves. Furthermore, a seemingly additive relationship between this botanical insecticide and $N$. tenuis was observed, although a greater decrease in whiteflies nymphs was observed in the treatment where $N$. tenuis acted alone. In addition, the insecticide lambda-cyhalothrin provided the greatest control of B. tabaci. By contrast, predators exposed to lambda-cyhalothrin exhibited the 

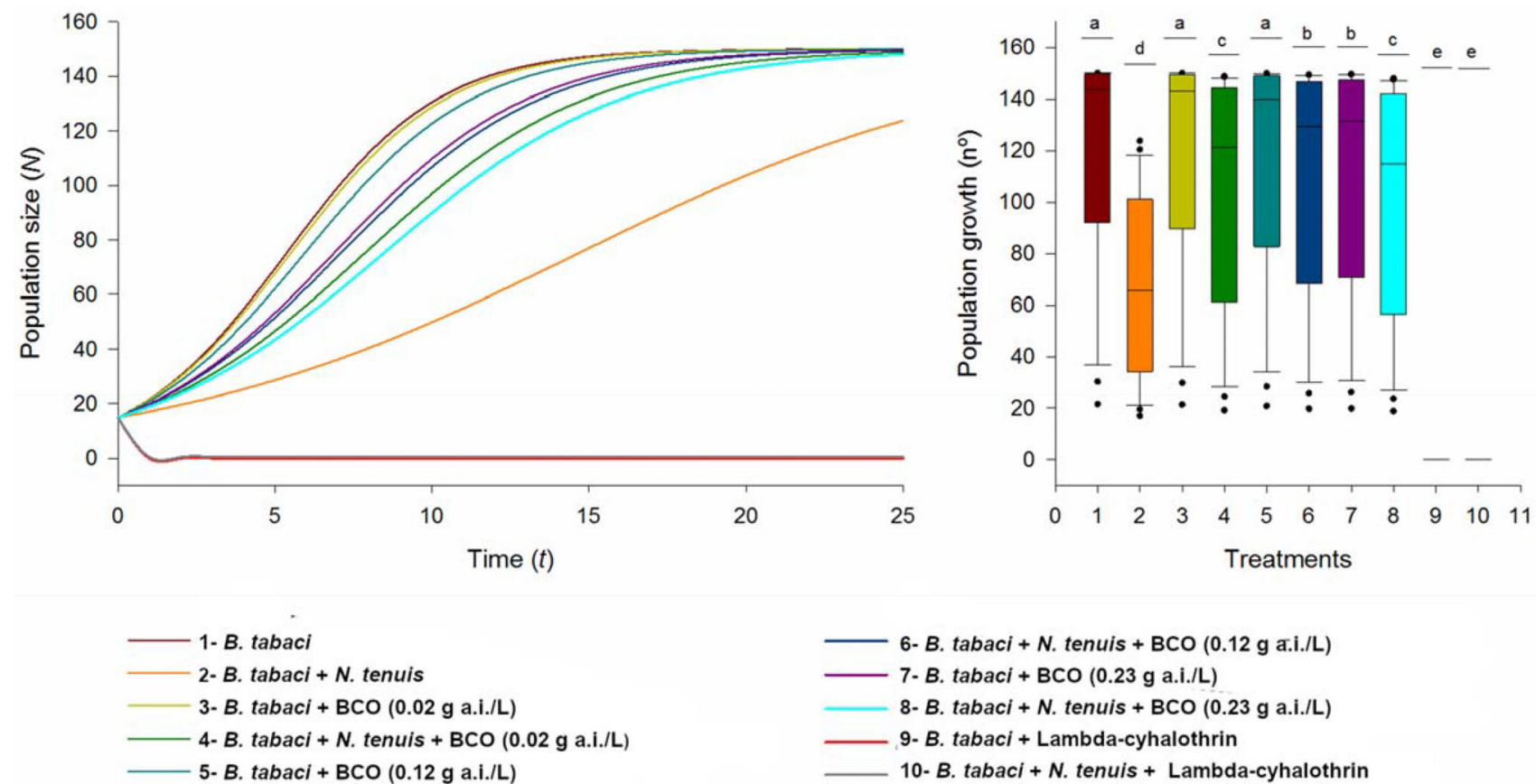

Figure 1 Curves and box plots of estimated population curves of Bemisia tabaci exposed to dry residues of borax plus citrus oil (BCO; at 10, 50 and $100 \%$ label concentration), lambda-cyhalothrin (treated control) and distilled water (untreated control). Box plots indicate the median and dispersion (lower and upper quartiles and outliers) population growth. Box plots with different lower-case letters are significantly different by pairwise comparison in $\chi^{2}$ log-rank test $(P \leq 0.05)$. [Color figure can be viewed at wileyonlinelibrary.com]

Table 2 Mean ( \pm SE) number of Nesidiocoris tenuis first, second, third and fourth instars produced by females exposed to dry residues of borax plus citrus oil (at 10,50 and 100\% label concentration), lambda-cyhalothrin (treated control) and distilled water (untreated control)

\begin{tabular}{|c|c|c|c|c|c|}
\hline \multirow[b]{2}{*}{ Treatment } & & \multicolumn{4}{|c|}{ Developmental stages of natural enemies* } \\
\hline & & First instar & Second instar & Third instar & Fourth instar \\
\hline \multirow[t]{5}{*}{ N. tenuis +} & Distilled water & $8.9 \pm 0.7 \mathrm{a}$ & $20.6 \pm 1.1 \mathrm{a}$ & $19.5 \pm 1.4 \mathrm{a}$ & $7.4 \pm 0.5 a$ \\
\hline & BCO $10 \%$ & $5.5 \pm 0.6 b$ & $14.3 \pm 1.2 b$ & $14.6 \pm 1.1 b$ & $5.0 \pm 0.4 b$ \\
\hline & BCO $50 \%$ & $4.5 \pm 0.6 b$ & $11.5 \pm 1.4 \mathrm{~b}$ & $9.7 \pm 1.4 c$ & $4.5 \pm 0.6 b$ \\
\hline & BCO $100 \%$ & $3.5 \pm 0.5 b$ & $6.7 \pm 0.5 c$ & $8.0 \pm 0.6 c$ & $4.2 \pm 0.5 b$ \\
\hline & Lambda-cyhalothrin & $0.0 \pm 0.0 \mathrm{c}$ & $0.0 \pm 0.0 \mathrm{~d}$ & $0.0 \pm 0.0 \mathrm{~d}$ & $0.0 \pm 0.0 c$ \\
\hline$F_{4,95}$ & & 30.81 & 57.43 & 48.09 & 32.32 \\
\hline$P$ & & $<0.001$ & $<0.001$ & $<0.001$ & $<0.001$ \\
\hline
\end{tabular}

greatest reduction in population growth and predation rate. The behavioral characteristics of $N$. tenuis were affected when predators were exposed to BCO and lambda-cyhalothrin.

Most toxicological studies involving botanical insecticides are based on the acute mortality of target species and natural enemies. ${ }^{57}$ However, after exposure to harmful compounds, insects can compensate their individual mortality in the population dynamics. ${ }^{42,58}$ Thus, insects are able to show logistic growth in the population, even after the mortality of some individuals. In our study, B. tabaci adults were able to reproduce and, consequently, increase their population even after exposure to BCO. The alternative hypothesis is as follows: (i) whiteflies are more susceptible to BCO during the nymphal stadium than during the egg and adult stages; (ii) serosal cells present in eggs could protect the embryo from BCO toxic compounds; ${ }^{59}$ and (iii) BCO does not have a large residual effect by contact against $B$. tabaci. By contrast, whitefly exhibited a decline in demographic parameters after exposure to lambda-cyhalothrin, which was also observed for $N$. tenuis.

Nesidiocoris tenuis is an effective predator of $B$. tabaci on tomato plants in greenhouses and open fields. ${ }^{60}$ Release of this predator in tomato crops may result in $>80 \%$ B. tabaci control. ${ }^{61}$ Despite the benefits provided by $N$. tenuis in terms of pest control, in some cases, use of insecticides and botanical insecticides is necessary in agricultural systems, especially when pests reach the economic damage threshold in crops. ${ }^{62,63}$ Our results showed that BCO and lambda-cyhalothrin caused a significant reduction in the emergence of $N$. tenuis nymphs. However, the sublethal effect on predator reproduction when exposed to both products cannot be considered similar. Nesidiocoris tenuis exposed to BCO showed an increase in its population growth curve. The same was not observed for lambda-cyhalothrin, which compromised the reproduction of the predators. 

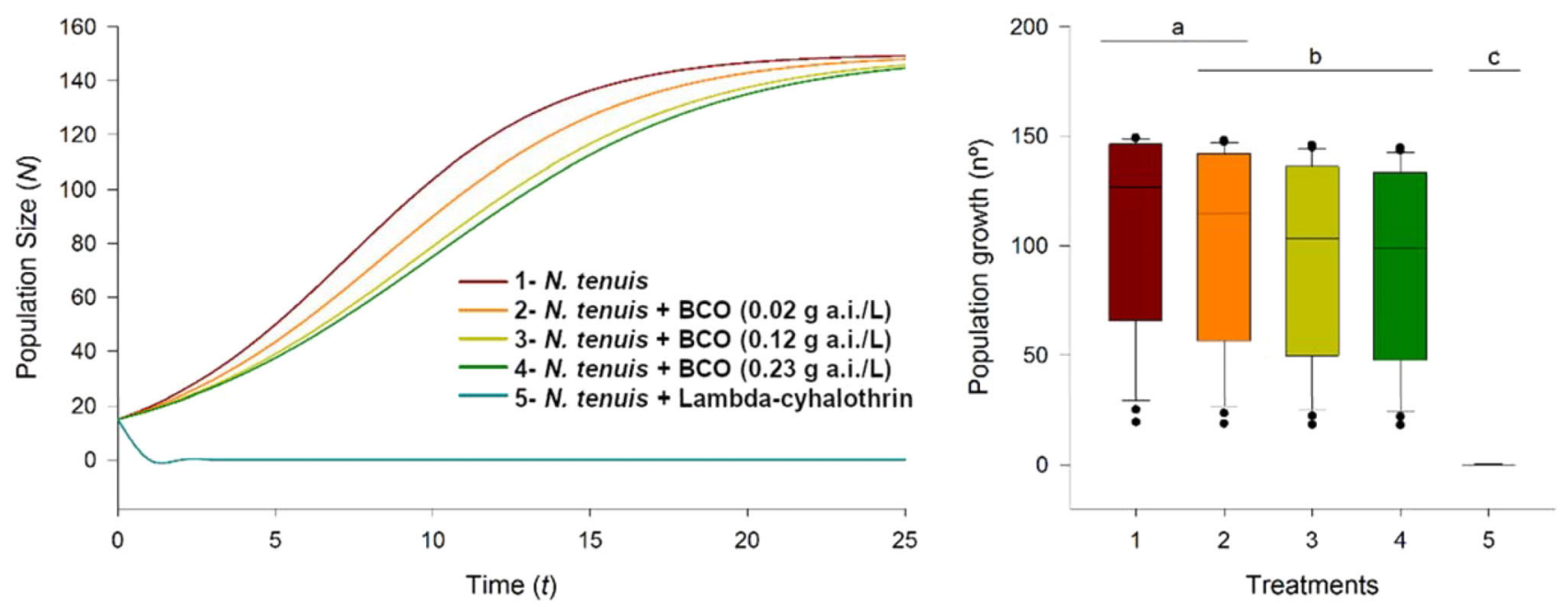

Figure 2 Curves and box plots of estimated population curves of Nesidiocoris tenuis exposed to dry residues of borax plus citrus oil (BCO; at 10, 50 and $100 \%$ label concentration), lambda-cyhalothrin (treated control) and distilled water (untreated control). Box plots indicate median and dispersion (lower and upper quartiles and outliers) population growth. Box plots with different lower case letters are significantly different by pairwise comparison in $\chi^{2}$ logrank test $(P \leq 0.05)$. [Color figure can be viewed at wileyonlinelibrary.com]

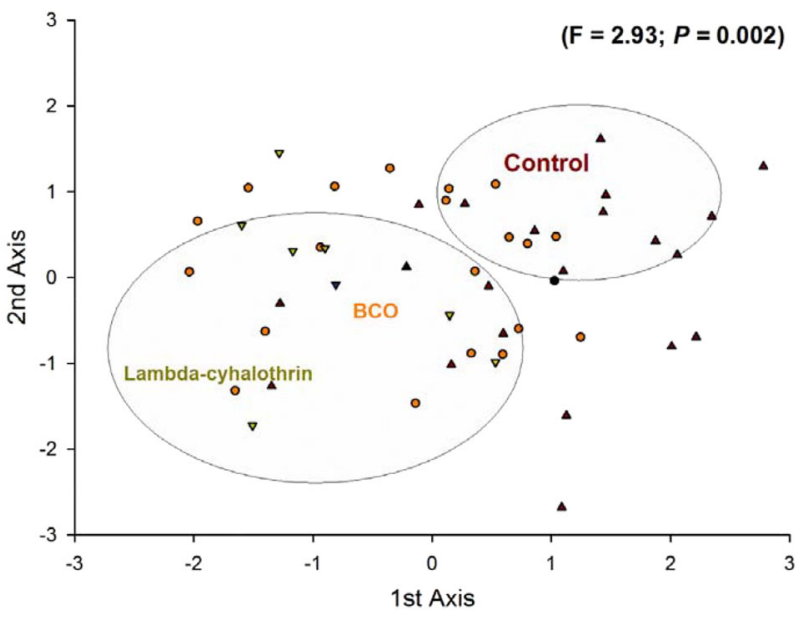

Figure 3 Ordination (CVA) diagrams showing divergence in predator behavior when exposed to dry residues of borax plus citrus oil (BCO; at 10, 50 and $100 \%$ label concentration), lambda-cyhalothrin (treated control) and distilled water (untreated control). Solid symbols represent individual replicates. Large circles indicate treatments that are not significantly different by the approximated $F$-test $(P \leq 0.05)$, based on the Mahalanobis $\left(D^{2}\right)$ distance between class means. [Color figure can be viewed at wileyonlinelibrary.com]

BCO did not reduce the longevity of $N$. tenuis, as reported for lambda-cyhalothrin, after exposure to dry residues of these products. $^{64}$ Another important generalist predator, Orius laevigatus (Fieber) (Hemiptera: Anthocoridae), did not have its longevity altered when exposed to BCO (at field concentration), suggesting that BCO has no effect on this biological trait in these predators. In turn, the number of $O$. laevigatus offspring was reduced after exposure to $\mathrm{BCO} .{ }^{48}$ However, no effects were observed on the survival and reproduction of adult females of the scale insect parasitoid Anagyrus pseudococci (Girault) (Hymenoptera: Encyrtidae) and the tomato leafminer parasitoid Bracon nigricans Szépligeti (Hymenoptera: Braconidae) when exposed to dry BCO residues. ${ }^{43,65}$

D-Limonene (the primary component of BCO) is a monocyclic terpene produced by plants as a secondary metabolite and is
Table 3 Canonical loadings (between canonical structures) of the canonical axes for the Nesidiocoris tenuis foraging behavior previously exposed to dry residues of borax plus citrus oil (at 10, 50 and $100 \%$ label concentration), lambda-cyhalothrin (treated control) and distilled water (untreated control)

\begin{tabular}{lcc} 
& \multicolumn{2}{c}{ Canonical axes } \\
\cline { 2 - 3 } Predator behavior & First & Second \\
\hline Resting & -0.55 & 0.47 \\
Preying & 0.68 & 0.08 \\
Plant feeding & 0.73 & -0.34 \\
Walking & -0.37 & 0.15 \\
Cleaning & $-\mathbf{0 . 9 9}$ & -0.92 \\
Fappr. & 2.93 & 0.11 \\
Proportion & 0.98 & 0.01 \\
P & $0.002^{*}$ & 0.974 \\
Eigenvalue & 0.61 & 0.01 \\
\hline
\end{tabular}

Bold type indicates the main contributors of each axis. *Significant axes.

often abundant in citrus peel. ${ }^{66}$ Interestingly, the mode of action of D-limonene-based biopesticides is similar to that described for lambda-cyhalothrin, which acts on the nervous systems of insects. ${ }^{67-70}$ This property could explain the results of our bioassays, in which both commercial products had detrimental effects on the behavioral response of $N$. tenuis. The undesirable sublethal effects on the predator behavioral response may lead to reductions in the reproductive rate, host search capacity and prey capture. ${ }^{64,67,71,72}$ In a behavioral follow-up study, we offered Tuta absoluta (Meyrick) (Lepidoptera: Gelechiidae) as prey for N. tenuis, and the predators spent more time walking and resting after exposure to $\mathrm{BCO}$ during the assessments. ${ }^{64}$ Moreover, the predation rate was lower compared to that of the untreated insects. Despite the results described above, in the same report, lambdacyhalothrin was more harmful to $N$. tenuis than BCO. ${ }^{64}$

The services provided by natural enemies during crop protection may be direct, by predation and/or parasitism, and indirect, 


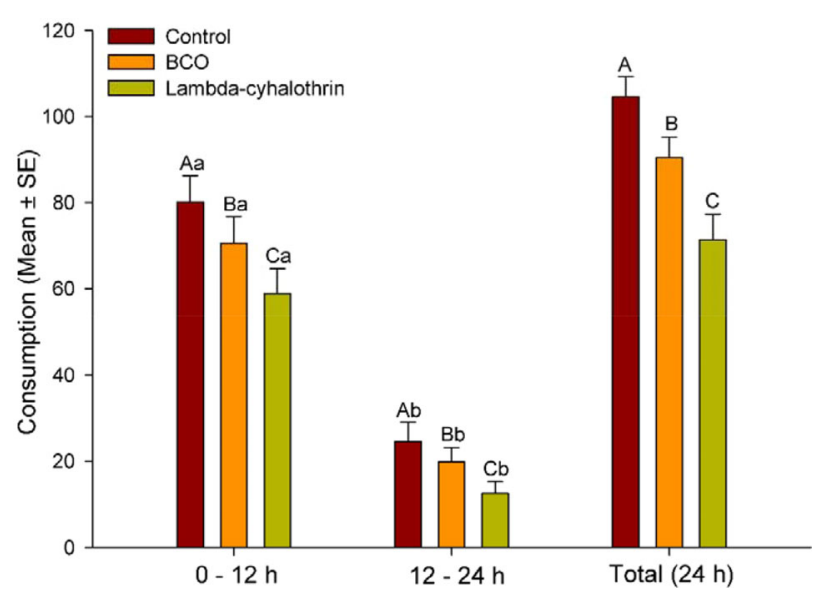

Figure 4 Mean $( \pm \mathrm{SE})$ consumption of Nesidiocoris tenuis females preying upon Bemisia tabaci after exposure to dry residues of borax plus citrus oil (BCO; 100\% label concentration), lambda-cyhalothrin (treated control) and distilled water (untreated control), at two times after exposure to the treatments ( $0-12 \mathrm{~h}$ and $12-24 \mathrm{~h}$ ), and total consumption after $24 \mathrm{~h}$. Bars followed by different capital letters are significantly different among treatments, and those followed by different lower case letters are significantly different between the two consumption times (GLM with Poisson distribution, followed by Tukey's test, $P \leq 0.05$ ). [Color figure can be viewed at wileyonlinelibrary.com]

by inhibiting the presence of herbivores, because these insects can recognize the chemical signals released by predators and/or parasitoids. ${ }^{21,73-75}$ Consequently, the importance of using harmless insecticides can be emphasized because, even with lower predation rates, the presence of predators is indirectly beneficial for tomato crops. In our results, $N$. tenuis had the highest predation rate in $B$. tabaci nymphs during the first evaluation, due to the fasting time ( $24 \mathrm{~h}$ ) before exposure to prey in the experimental areas. Furthermore, both compounds promoted a reduction in the number of $B$. tabaci nymphs preyed on by $N$. tenuis. The same products decreased the total predation rate of $N$. tenuis over T. absoluta in a laboratory bioassay. ${ }^{64}$ The undesirable interference in predatory behavior after insecticide exposure can be characterized by the: (i) repellent effect, (ii) anti-alimentary properties, and (iii) interruption in the ability to locate prey. ${ }^{30,71}$ We suggest that hypothesis (iii) is applicable here because both commercial products could trigger random movements and increase insect restlessness. $^{76}$

In summary, despite the smaller effect of BCO on the demographic parameters of $B$. tabaci, use of this type of botanical insecticide should be prioritized instead of lambda-cyhalothrin in IPM programs. BCO could act simultaneously with $N$. tenuis against $B$. tabaci, which was not noted for predators exposed to lambdacyhalothrin. Bemisia tabaci was exposed via residual contact with dry residues; however, direct topical spraying on nymphs and adults may provide more effective pest control. Consequently, direct topical spraying could have additional negative effects on the predator. Thus, to achieve the maximum potential of both control methods, BCO should be employed at first aiming to reduce the $B$. tabaci population. Since this commercial product is considered to have low persistence in agronomic environments ( $\sim 7$ days, according to the manufacturer), N. tenuis could be released as a second line of defenze on tomato crops. It may also be worth evaluating the sublethal effects of BCO on $N$. tenuis under commercial conditions, as this predator could avoid treated tomato plants, thus reducing the damage caused to its biological characteristics by pesticides.

\section{ACKNOWLEDGEMENTS}

The authors would like to thank Philippe Bearez, Edwige AmiensDesneux and Christiane Metay-Merrien from INRA for technical assistance and the Coordination of Superior Level Staf Improvement -Capes (grant number: 88881.132785/2016-2101), Minas Gerais State Foundation for Research (FAPEMIG) and National Council for Scientifc and Technological Development (CNPq) for provide funding to MAS (Ph.D. fellowship), the project EUCLID (H2020-SFS-2014, grant number: 633999) for funding to ND, and the project STomP (ARIMnet2, grant agreement: 618127) for funding to ND, A-VL, AB and LZ. ND and MC were supported by the IPM Innovation Lab (AID-OAA-14-000018).

\section{REFERENCES}

1 Oliveira MRV, Henneberry TJ and Anderson P, History, current status, and collaborative research projects for Bemisia tabaci. Crop Prot 20: 709-723 (2001)

2 De Barro PJ, Liu S-S, Boykin LM and Dinsdale AB, Bemisia tabaci: a statement of species status. Annu Rev Entomol 56:1-19 (2011).

3 Horowitz AR, Antignus Y and Gerling D, Management of Bemisia tabaci whiteflies, in The Whitefly, Bemisia tabaci (Homoptera: Aleyrodidae) Interaction with Geminivirus-Infected Host Plants. Netherlands: Springer, pp. 293-322 (2011).

4 Quintela ED, Abreu AG, dos Lima JFS, Mascarin GM, dos Santos JB and Brown JK, Reproduction of the whitefly Bemisia tabaci (Hemiptera: Aleyrodidae) B biotype in maize fields (Zea mays L.) in Brazil. Pest Manag Sci 72:2181-2187 (2016).

5 Taggar GK and Gill RS, Host plant resistance in Vigna sp. towards whitefly, Bemisia tabaci (Gennadius): a review. Entomol Gen 1:1-24 (2016).

6 Navas-Castillo J, Fiallo-Olivé E and Sánchez-Campos S, Emerging virus diseases transmitted by whiteflies. Annu Rev Phytopathol 49: 219-248 (2011).

7 Gilbertson RL, Batuman O, Webster CG and Adkins S, Role of the insect supervectors Bemisia tabaci and Frankliniella occidentalis in the emergence and global spread of plant viruses. Annu Rev Virol 2: 67-93 (2015).

8 Boykin LM, Bell CD, Evans G, Small I and De Barro PJ, Is agriculture driving the diversification of the Bemisia tabaci species complex (Hemiptera: Sternorrhyncha: Aleyrodidae)?: Dating, diversification and biogeographic evidence revealed. BMC Evol Biol 13:1-10 (2013).

9 Ellsworth PC and Martinez-Carrillo JL, IPM for Bemisia tabaci: a case study from North America. Crop Prot 20:853-869 (2001).

10 Palumbo JC, Horowitz AR and Prabhaker N, Insecticidal control and resistance management for Bemisia tabaci. Crop Prot 20:739-765 (2001).

11 Liang P, Tian Y-A, Biondi A, Desneux N and Gao X-W, Short-term and transgenerational effects of the neonicotinoid nitenpyram on susceptibility to insecticides in two whitefly species. Ecotoxicology 21: 1889-1898 (2012).

12 Roditakis E, Grispou M, Morou E, Kristoffersen JB, Roditakis N, Nauen R et al., Current status of insecticide resistance in $\mathrm{Q}$ biotype Bemisia tabaci populations from Crete. Pest Manag Sci 65:313-322 (2009).

13 Bass C, Denholm I, Williamson MS and Nauen R, The global status of insect resistance to neonicotinoid insecticides. Pestic Biochem Physiol 121:78-87 (2015).

14 Dângelo RAC, Michereff-Filho M, Campos MR, da Silva PS and Guedes RNC, Insecticide resistance and control failure likelihood of the whitefly Bemisia tabaci (MEAM1; B biotype): a Neotropical scenario. Ann Appl Biol 172:88-99 (2018).

15 Lykouressis DP, Perdikis DCH and Konstantinou AD, Predation rates of Macrolophus pygmaeus (Hemiptera: Miridae) on different densities of eggs and nymphal instars of the greenhouse whitefly Trialeurodes vaporariorum (Homoptera: Aleyrodidae). Entomol Gen 32:105-112 (2009).

16 Bonato O, Deschamps C, Hamdi F, Ridray G and Chadoeuf J, Spatiotemporal distribution of Macrolophus caliginosus in protected tomato crop (Heteroptera: Miridae). Entomol Gen 33:91-102 (2011).

17 Perdikis D and Arvaniti K, Nymphal development on plant vs. leaf with and without prey for two omnivorous predators: Nesidiocoris tenuis (Reuter, 1895)(Hemiptera: Miridae) and Dicyphus errans (Wolff, 1804)(Hemiptera: Miridae). Entomol Gen 35:297-306 (2016). 
18 Passos LC, Soares MA, Costa MA, Michaud JP, Freire BC and Carvalho GA, Physiological susceptibility of the predator Macrolophus basicornis (Hemiptera: Miridae) to pesticides used to control of Tuta absoluta (Lepidoptera: Gelechiidae). Biocontrol Sci Technol 27:1082-1095 (2017).

19 Passos LC, Soares MA, Collares LJ, Malagoli I, Desneux N and Carvalho GA, Lethal, sublethal and transgenerational effects of insecticides on Macrolophus basicornis, predator of Tuta absoluta. Entomol Gen 38:127-143 (2018).

20 Pérez-Valencia $\mathrm{LI}$, Camorlinga-Cortés $\mathrm{P}$, Carrillo-Arámbula LC, Palmeros-Suárez PA and Ramirez-Romero R, Why can a predator increase its consumption of prey when it is released along with a parasitoid? Entomol Gen 39:205-219 (2019).

21 Pérez-Hedo $M$, Urbaneja-Bernat $P$, Jaques JA, Flors $V$ and Urbaneja $A$, Defensive plant responses induced by Nesidiocoris tenuis (Hemiptera: Miridae) on tomato plants. J Pest Sci 88:543-554 (2015).

22 Zappalà L, Biondi A, Alma A, Al-Jboory IJ, Arnò J, Bayram A et al., Natural enemies of the south American moth, Tuta absoluta, in Europe, North Africa and Middle East, and their potential use in pest control strategies. J Pest Sci 86:635-647 (2013).

23 Jaworski CC, Chailleux A, Bearez P and Desneux N, Apparent competition between major pests reduces pest population densities on tomato crop, but not yield loss. J Pest Sci 88:793-803 (2015).

24 Biondi A, Guedes RNC, Wan F-H and Desneux N, Ecology, worldwide spread, and management of the invasive South American tomato pinworm, Tuta absoluta: past, present, and future. Annu Rev Entomol 63:239-258 (2018).

25 Mansour R, Brévault T, Chailleux A, Cherif A, Grissa-Lebdi K, Haddi K et al., Occurrence, biology, natural enemies and management of Tuta absoluta in Africa. Entomol Gen 38:83-112 (2018).

26 Jaworski CC, Bompard A, Genies L, Amiens-Desneux E and Desneux N, Preference and prey switching in a generalist predator attacking local and invasive alien pests. PLoS One 8:1-10 (2013).

27 Sylla S, Brévault T, Diarra K, Bearez P and Desneux N, Life-history traits of Macrolophus pygmaeus with different prey foods. PLoS One 11: 1-8 (2016).

28 Bouagga S, Urbaneja A and Pérez-Hedo M, Comparative biocontrol potential of three predatory mirids when preying on sweet pepper key pests. Biol Control 121:168-174 (2018).

29 Wheeler AG and Krimmel BA, Mirid (Hemiptera: Heteroptera) specialists of sticky plants: adaptations, interactions, and ecological implications. Annu Rev Entomol 60:393-414 (2015).

30 Desneux N, Decourtye A and Delpuech J-M, The sublethal effects of pesticides on beneficial arthropods. Annu Rev Entomol 52:81-106 (2007).

31 Wanumen AC, Sánchez-Ramos I, Viñuela E, Medina P and Adán Á, Impact of feeding on contaminated prey on the life parameters of Nesidiocoris tenuis (Hemiptera: Miridae) adults. J Insect Sci 16:1-7 (2016).

32 Campolo O, Cherif A, Ricupero M, Siscaro G, Grissa-Lebdi K, Russo A et al., Citrus peel essential oil nanoformulations to control the tomato borer, Tuta absoluta: chemical properties and biological activity. Sci Rep 7:13036 (2017).

33 Chaieb I, Zarrad K, Sellam R, Tayeb W, Hammouda AB, Laarif A et al., Chemical composition and aphicidal potential of Citrus aurantium peel essential oils. Entomol Gen 37:63-75 (2018).

34 Hatt S, Xu Q, Francis F and Osawa N, Aromatic plants of east asia to enhance natural enemies towards biological control of insect pests, a review. Entomol Gen 38:275-315 (2019).

35 Benelli G, Pavel R, Zorzetto C, Sánchez-Mateo CC, Santini G, Canale A et al., Insecticidal activity of the essential oil from Schizogyne sericea (Asteraceae) on four insect pests and two non-target species. Entomol Gen 39:9-18 (2019).

36 Petrović M, Popović A, Kojić D, Šućur J, Bursić V, Aćimović $M$ et al., Assessment of toxicity and biochemical response of Tenebrio molitor and Tribolium confusum exposed to Carum carvi essential oil. Entomol Gen 38:333-348 (2019).

37 Moreno SC, Carvalho GA, Picanço MC, Morais EGF and Pereira RM, Bioactivity of compounds from Acmella oleracea against Tuta absoluta (Meyrick) (Lepidoptera: Gelechiidae) and selectivity to two non-target species. Pest Manag Sci 68:386-393 (2012).

38 Isman MB, A renaissance for botanical insecticides? Pest Manag Sci 71: 1587-1590 (2015)

39 Bacci L, da Silva ÉM, Martins JC, Soares MA, de Campos MR and Picanço MC, Seasonal variation in natural mortality factors of Tuta absoluta (Lepidoptera: Gelechiidae) in open-field tomato cultivation. J Appl Entomol 143:21-33 (2019).

40 Drobnjaković $T$, Marčić $D$, Prijović $M$, Perić $P$, Milenković $S$ and Bošković J, Life history traits and population growth of Encarsia formosa Gahan (Hymenoptera: Aphelinidae) local population from Serbia. Entomol Gen 35:281-295 (2016).

41 Stark JD, Tanigoshi L, Bounfour M and Antonelli A, Reproductive potential: its influence on the susceptibility of a species to pesticides. Ecotoxicol Environ Saf 37:273-279 (1997).

42 Stark JD, Banks JE and Acheampong S, Estimating susceptibility of biological control agents to pesticides: influence of life history strategies and population structure. Biol Control 29:392-398 (2004).

43 Biondi A, Zappalà L, Stark JD and Desneux N, Do biopesticides affect the demographic traits of a parasitoid wasp and its biocontrol services through sublethal effects? PLoS One 8:e76548 (2013).

44 Amarasekare KG, Shearer PW and Mills NJ, Testing the selectivity of pesticide effects on natural enemies in laboratory bioassays. Biol Control 102:7-16 (2016).

45 Jam NA and Saber M, Sublethal effects of imidacloprid and pymetrozine on the functional response of the aphid parasitoid, Lysiphlebus fabarum. Entomol Gen 38:173-190 (2018).

46 Zhang Y, Guo L, Atlihan R, Chi H and Chu D, Demographic analysis of progeny fitness and timing of resurgence of Laodelphax striatellus after insecticides exposure. Entomol Gen 39:221-230 (2019).

47 Ovchinnikov AN, Belyakova NA, Ovchinnikova AA and Reznik SY, Factors determining larval cannibalistic behavior in invasive and native populations of the multicolored Asian ladybird, Harmonia axyridis. Entomol Gen 38:243-254 (2019).

48 Biondi A, Desneux N, Siscaro G and Zappalà L, Using organic-certified rather than synthetic pesticides may not be safer for biological control agents: selectivity and side effects of 14 pesticides on the predator Orius laevigatus. Chemosphere 87:803-812 (2012).

$49 \mathrm{Kim}$ JG, Lee WH, Yu YM, Yasunaga-Aoki C and Jung SH, Lifecycle, biology, and descriptions of greenhouse biological control agent, Nesidiocoris tenuis (Reuter, 1895) (Hemiptera: Miridae). J Fac Agric Kyushu Univ 61:313-318 (2016).

50 Walthall WK and Stark JD, Comparison of two population-level ecotoxicological endpoints: the intrinsic (rm) and instantaneous (ri) rates of increase. Environ Toxicol Chem 16:1068-1073 (1997).

51 Junior CFC, Pederiva CN, Bose RC, Garcia VA, Lino-de-Oliveira C and Marino-Neto J, ETHOWATCHER: validation of a tool for behavioral and video-tracking analysis in laboratory animals. Comput Bio Med 42:257-264 (2012).

52 Shapiro SS and Wilk MB, An analysis of variance test for normality (complete samples). Biometrika 52:591-611 (1965).

53 Bartlett MS, Properties of sufficiency and statistical tests. Proc $R$ Soc Lond A 160:268-282 (1937).

54 Naranjo SE, Chu C-C and Henneberry TJ, Economic injury levels for Bemisia tabaci (Homoptera: Aleyrodidae) in cotton: impact of crop price, control costs, and efficacy of control. Crop Prot 15:779-788 (1996).

55 Guedes RNC, Smagghe G, Stark JD and Desneux N, Pesticide-induced stress in arthropod pests for optimized integrated pest management programs. Annu Rev Entomol 61:43-62 (2016).

56 Wang Z, Dai P, Yang X, Ruan C, Biondi A, Desneux N et al., Selectivity of novel and traditional insecticides used for management of whiteflies on the parasitoid Encarsia formosa. Pest Manag Sci 75: 2716-2724 (2019).

57 Regnault-Roger C, Vincent C and Arnason JT, Essential oils in insect control: low-risk products in a high-stakes world. Annu Rev Entomol 57:405-424 (2012).

58 McNair JB, Is there a place for ecotoxicology? SETAC News 15:18-21 (1995).

59 Berger-Twelbeck P, Hofmeister P, Emmling S and Dorn A, Ovicideinduced serosa degeneration and its impact on embryonic development in Manduca sexta (Insecta: Lepidoptera). Tissue Cell 35:101-112 (2003).

60 Calvo FJ, Bolckmans $\mathrm{K}$ and Belda JE, Release rate for a pre-plant application of Nesidiocoris tenuis for Bemisia tabaci control in tomato. BioControl 57:809-817 (2012).

61 Calvo J, Bolckmans K, Stansly PA and Urbaneja A, Predation by Nesidiocoris tenuis on Bemisia tabaci and injury to tomato. BioControl 54: 237-246 (2009).

62 Zappalà L, Siscaro G, Biondi A, Mollá O, González-Cabrera J and Urbaneja A, Efficacy of sulphur on Tuta absoluta and its side effects 
on the predator Nesidiocoris tenuis. J Appl Entomol 136:401-409 (2012).

63 Madbouni MAZ, Samih MA, Qureshi JA, Biondi A and Namvar P, Compatibility of insecticides and fungicides with the zoophytophagous mirid predator Nesidiocoris tenuis. PLoS One 12: e0187439 (2017).

64 Soares MA, Campos MR, Passos LC, Carvalho GA, Haro MM, Lavoir AV et al., Botanical insecticide and natural enemies: a potential combination for pest management against Tuta absoluta. J Pest Sci 92: 1433-1443 (2019).

65 Mansour R, Suma P, Mazzeo G, Lebdi KG and Russo A, Evaluating side effects of newer insecticides on the vine mealybug parasitoid Anagyrus sp. near pseudococci, with implications for integrated pest management in vineyards. Phytoparasitica 39: 369-376 (2011).

66 Ciriminna R, Lomeli-Rodriguez M, Cara PD, Lopez-Sanchez JA and Pagliaro $M$, Limonene: a versatile chemical of the bioeconomy. Chem Commun 50:15288-15296 (2014).

67 Desneux N, Rafalimanana $\mathrm{H}$ and Kaiser L, Dose-response relationship in lethal and behavioural effects of different insecticides on the parasitic wasp Aphidius ervi. Chemosphere 54:619-627 (2004).

68 Desneux N, Pham-Delègue $M$ and Kaiser L, Effects of sub-lethal and lethal doses of lambda-cyhalothrin on oviposition experience and host-searching behaviour of a parasitic wasp, Aphidius ervi. Pest Manag Sci 60:381-389 (2004).
69 Malacrinò A, Campolo O, Laudani F and Palmeri V, Fumigant and repellent activity of limonene enantiomers against Tribolium confusum du Val. Neotrop Entomol 45:597-603 (2016).

70 Mossa ATH, Green pesticides: essential oils as biopesticides in insectpest management. J Environ Sci Technol 9:354-378 (2016).

71 Müller C, Impacts of sublethal insecticide exposure on insects-facts and knowledge gaps. Basic Appl Ecol 30:1-10 (2018).

72 Soares MA, Passos LC, Campos MR, Collares L, Desneux N and Carvalho GA, Side effects of insecticides commonly used against Tuta absoluta on the predator Macrolophus basicornis. J Pest Sci 92 : 1447-1456 (2019).

73 Nomikou M, Janssen A and Sabelis MW, Herbivore host plant selection: whitefly learns to avoid host plants that harbour predators of her offspring. Oecologia 136:484-488 (2003).

74 Messelink GJ, Sabelis MW and Janssen A, Generalist Predators, Food Web Complexities and Biological Pest Control in Greenhouse Crops, in Integrated Pest Management and Pest Control-Current and Future Tactics. InTech, London, pp. 191-214 (2012).

75 Desneux N, Kaplan I, Yoo HJS, Wang S and O'Neil RJ, Temporal synchrony mediates the outcome of indirect effects between prey via a shared predator. Entomol Gen 39:127-136 (2019).

$76 \mathrm{He} \mathrm{Y,} \mathrm{Zhao} \mathrm{J,} \mathrm{Zheng} \mathrm{Y,} \mathrm{Desneux} \mathrm{N} \mathrm{and} \mathrm{Wu} \mathrm{K,} \mathrm{Lethal} \mathrm{effect} \mathrm{of} \mathrm{imidaclo-}$ prid on the coccinellid predator Serangium japonicum and sublethal effects on predator voracity and on functional response to the whitefly Bemisia tabaci. Ecotoxicology 21:1291-1300 (2012). 